\title{
Management of cerebral vasospasm following aneurysmal subarachnoid hemorrhage
}

\author{
Mohamed Shehabeldin MD, Yazan J Alderazi MD
}

\begin{abstract}
Cerebral vasospasm is a serious complication following aneurysmal subarachnoid hemorrhage (SAH); it causes delayed cerebral ischemia (DCl) or infarction. Arterial vasospasm is considered the most common cause of disability and mortality among survivors of aneurysmal $\mathrm{SAH}$. Monitoring for vasospasm is extremely important starting from the first day following a hemorrhage. The mechanism of vasospasm is not completely understood, but most data and studies link the incidence of vasospasm to inflammatory responses secondary to extravasation of blood into the subarachnoid space. It is essential for critical care teams and health care providers caring for patients with aneurysmal SAH to understand the clinical presentation and management of cerebral vasospasm. In our review, we focus on the guidelines for monitoring and basic management of vasospasm and DCl which include monitoring options, hemodynamic and endovascular therapy, triggers for intervention, and triggers for treatment de-escalation.
\end{abstract}

Keywords: cerebral vasospasm, aneurysmal subarachnoid hemorrhage, delayed cerebral ischemia, transcranial Doppler, nimodipine

\section{INTRODUCTION}

Cerebral vasospasm is a progressive narrowing of the cerebral arteries following aneurysmal subarachnoid hemorrhage (SAH), ${ }^{1}$ triggered by neuro-inflammatory processes, ${ }^{2}$ and consequently leading to delayed cerebral ischemia $(\mathrm{DCl}){ }^{3}$ The incidence of vasospasm peaks 7-10 days after saccular aneurysm rupture; it can occur up to 21 days $^{4}$ and is increased in patients who undergo aneurysmal coiling between 4-10 days compared with those who undergo coiling between 0-3 days. ${ }^{5}$ The risk of developing vasospasm is usually directly proportional to the volume of blood in the SAH. ${ }^{6}$ Ischemic events secondary to vasospasm lead to confusion and decreased level of consciousness with focal

Corresponding author: Mohamed Shehab-Eldin Contact Information: Mohamed.shehab-eldin@ ttuhsc.edu

DOI: 10.12746/swrccc.v5i20.410 neurological deficits which may be preceded by worsening headache and increased blood pressure. ${ }^{1}$ In 1951, cerebral artery spasm was first described using cerebral angiography by percutaneous puncture of the carotid artery, ${ }^{7}$ followed by a few studies describing the time course of vasospasm. ${ }^{8}$

\section{KEY DEFINITIONS}

The definition of cerebral vasospasm depends on the era and tool used to define the vasospasm. In 1951, Ecker and Riemenschneider defined arterial vasospasm as recognized arteriographically when a vessel is a larger caliber in a subsequent angiogram than it was in a prior angiogram under identical circumstances. ${ }^{7}$

Later, angiographic vasospasm was defined as narrowing of the dye column in the major cerebral arteries, which is usually focal but can be diffuse and is rarely identified before day 4 following aneurysmal $\mathrm{SAH} .{ }^{1}$ Clinical vasospasm, as a syndrome, occurs 
due to ischemic events secondary to cerebral artery narrowing, characterized by the insidious onset of confusion, decreased consciousness, and worsening headache which may be associated with increased blood pressure. ${ }^{1}$

During the current era, definitions of vasospasm have expanded to include clinical or symptomatic vasospasm, angiographic vasospasm, and transcranial Doppler (TCD) vasospasm. Clinical or symptomatic vasospasm has the same definition as in earlier periods but requires ruling out other possible causes of worsening symptoms, such as hydrocephalus, seizures, infections, fever, metabolic imbalances, and oversedation. ${ }^{9}$ Angiographic or radiologic vasospasm is categorized by the degree of narrowing; $1-50 \%$ is mild vasospasm, $51-75 \%$ is moderate, and $>75 \%$ is severe vasospasm. ${ }^{10,11}$ It can involve proximal vessels, distal vessels, or both and does not necessarily manifest as clinical vasospasm. Transcranial Doppler vasospasm is defined as a mean flow velocity in the middle cerebral artery (MCA) that exceeds $120 \mathrm{~cm} / \mathrm{sec}$, or Lindegaard ratio (middle cerebral artery mean flow velocity/extracranial internal carotid artery mean flow velocity) $>6 .^{9,10}$ Delayed cerebral ischemia (DCl) is a neurologic deterioration presumed secondary to cerebral ischemia that cannot be explained by other systemic or neurologic condition and lasts for more than 1 hour. ${ }^{12}$

\section{EPIDEMIOLOGY OUTCOMES OF ANEURYSMAL SAH}

Subarachnoid hemorrhage is one of the most challenging neurological emergencies. The incidence of aneurysmal SAH is 2 to 16 per 100,000 population..$^{4,12}$ In the United States, the incidence is 9.7 per 100,000 population. ${ }^{4,13}$ The median case fatality rate (CFR) in the US was $32.2 \%$ and has declined over the last three decades; the CFR is higher in Europe and lower in Japan. ${ }^{14}$ In $50 \%$ of cases, large artery narrowing will evolve to be visible angiographically and causes ischemic neurological symptoms. ${ }^{4}$

\section{Pathophysiology}

Rupture of a cerebral aneurysm results in deposition of blood in the subarachnoid space and release of free hemoglobin. ${ }^{2,15}$ Consequently, microglia, the immunomodulatory cells in the central nervous system (CNS), are activated. ${ }^{15}$ Microglia stimulate cell adhesion molecules on the luminal surface of endothelial cells, ${ }^{15}$ which allows peripheral immune cells like macrophages and neutrophils to bind to endothelial cells and enter the subarachnoid space to clear the free hemoglobin. ${ }^{2,15}$ The absence of lymphatics in the CNS, impaired cerebrospinal fluid (CSF) circulation due to $S A H,{ }^{2}$ and the restoration of endothelial tight junction barriers ${ }^{15}$ trap macrophages and neutrophils in the subarachnoid space. ${ }^{2,15}$ These trapped cells undergo degranulation and release of inflammatory factors, like endothelin and free radicals; this inflammatory process induces arterial vasoconstriction. ${ }^{2,15}$ There are two phases of this inflammatory process, an initial or acute phase occurs 1-3 days after the primary injury, ${ }^{16}$ mediated by macrophages and neutrophils, and a delayed phase, mediated by inflammatory products from degranulation of the acute phase cells, occurs in days to weeks. ${ }^{2}$

Cortical spreading depression (CSD) or cortical depolarization is a phenomenon described in several neurological injuries. It was first hypothesized to be a part of the migraine pathophysiology ${ }^{17}$ recently it was related to $\mathrm{DCl}$ following aneurysmal $\mathrm{SAH} .{ }^{18}$ Cortical spreading depression is a self-propagating wave of neuronal and glial depolarization, redistribution of ions inside and outside brain cells, and eventual loss of membrane potential. ${ }^{19-21}$ As a response to brain injury, glutamate is released leading to stimulation of sodium and calcium channels which results in cation influx and neuronal swelling. This process is described as a glutamate excito-toxicity. To restore the normal membrane gradient, oxygen and energy requirements of cells and ion pumps increase to reverse the disrupted ionic hemostasis. In healthy brain tissue, hyperemia induced by vasodilation via nitric oxide and arachidonic acid metabolites increases blood flow and consequently oxygen delivery and is a normal hemodynamic response. However, in injured cells after aneurysmal $\mathrm{SAH}$, this process of hyperemia fails and is replaced by vasoconstriction (inverse of the normal hemodynamic response) and consequently hypo-perfusion and ischemia. Cortical spreading depression continues to "spread the ischemia" to surrounding brain tissues. ${ }^{18-21}$ 


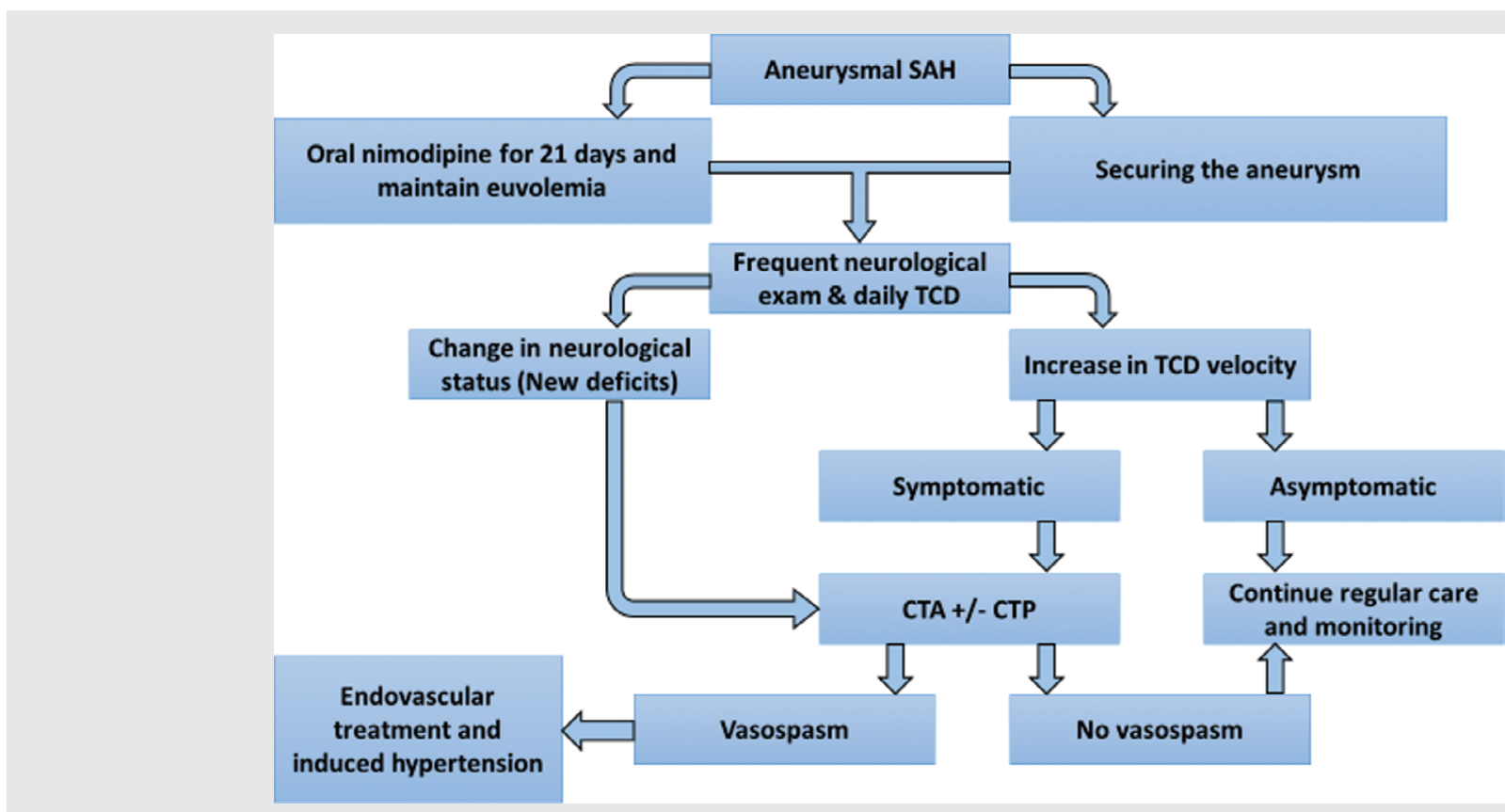

Figure 1. Sample algorithm for management of cerebral vasospasm. The algorithm can be modified depending on available modalities for monitoring. Separate algorithms for good grade and poor grade patients may be reasonable at some institutions.

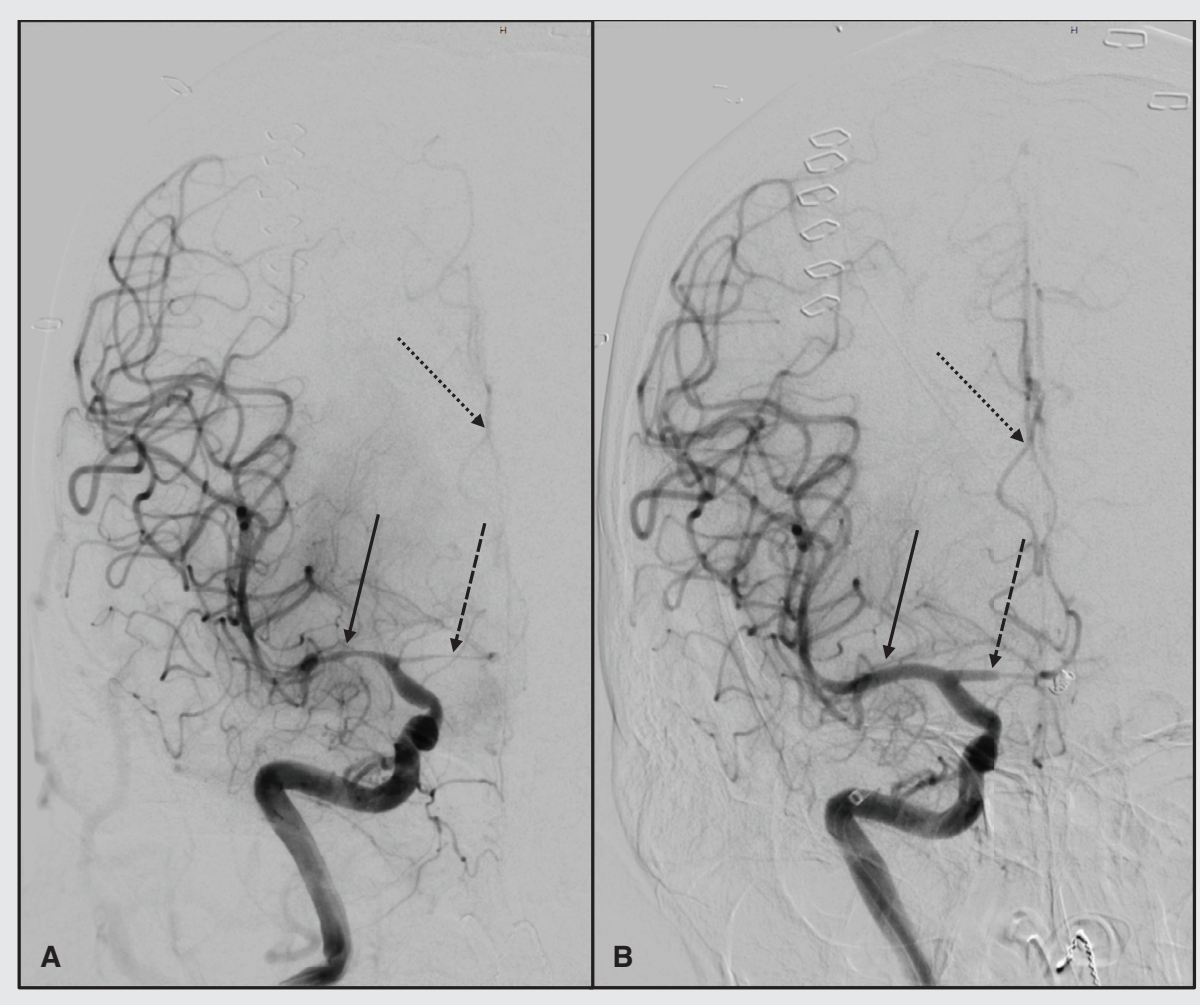

Figure 2. Cerebral angiograms of the internal carotid artery, PA cranial view, demonstrating pre-angioplasty (A) and post-angioplasty (B), improvement of arterial caliber in the middle cerebral artery M1 segment (solid arrows), anterior cerebral artery A1 segment (dashed arrows) and the distal anterior cerebral artery perfusion (dotted arrows). 
Box 1. Key points in cerebral vasospasm after aneurysm subarachnoid hemorrhage

- Cerebral vasospasm is the major determinant of disability and mortality after aneurysmal subarachnoid hemorrhage after the aneurysm has been secured.

- Monitoring is clinical, radiographic, and physiologic.

- Cerebral vasospasm is a monophasic illness that typically lasts days.

- The main endpoints triggering de-escalation of therapy are resolution of vasospasm or a significant established infarction in the territory at risk.

- The main therapeutic modalities are nimodipine, induced euvolemic hypertension, and endovascular therapy.

\section{MANAGEMENT}

Delayed cerebral ischemia secondary to vasospasm accounts for the highest burden of disability and mortality in aneurysmal SAH survivors. This requires monitoring and management starting from the first day after aneurysmal rupture. The guidelines from the Neurocritical Care Society ${ }^{22}$ and the American
Heart Association and American Stroke Association (AHA/ASA $)^{4}$ divide management for patients following aneurysmal SAH into monitoring and treatment. Monitoring for $\mathrm{DCl}$ is clinical, radiographic, and physiological (Table 1). Treatment and intervention usually depend on identifying triggers during monitoring and includes oral nimodipine, hemodynamic management, and endovascular intervention.

\section{A. Monitoring}

Serial neurological examinations, physiological monitoring, and radiological studies all have an essential role in identifying triggers for intervention (Table 2). Clinical examination mainly identifies new neurological deficits; it requires a skilled nursing staff and physicians to recognize subtle changes in the patient's neurological status which might be a sign of vasospasm and $\mathrm{DCl}$. Neurological examination as a part of monitoring is essential despite its limitations in detecting subtle changes in poor grade patients.

Transcranial Doppler (TCD) is the most commonly used physiological modality to monitor for vasospasm. Transcranial Doppler is a noninvasive method for measuring cerebral vessels' diameter and blood

Table 1. AHA/ASA summary of recommendations for management of cerebral vasospasm and delayed cerebral ischemia after aneurysmal $\mathrm{SAH}^{4}$

1. Oral nimodipine should be administered to all patients with aneurysmal SAH (Class I; Level of Evidence A). (It should be noted that this agent has been shown to improve neurological outcomes but not cerebral vasospasm. The value of other calcium antagonists, whether administered orally or intravenously, remains uncertain)

2. Maintenance of euvolemia and normal circulating blood volume is recommended to prevent DCI (Class I; Level of Evidence B). (Revised recommendation from previous guidelines)

3. Prophylactic hypervolemia or balloon angioplasty before the development of angiographic spasm is not recommended (Class III; Level of Evidence B). (New recommendation)

4. Transcranial Doppler is reasonable to monitor for the development of arterial vasospasm (Class IIa; Level of Evidence B). (New recommendation)

5. Perfusion imaging with $\mathrm{CT}$ or magnetic resonance can be useful to identify regions of potential brain ischemia (Class IIa; Level of Evidence B). (New recommendation)

6. Induction of hypertension is recommended for patients with DCI unless blood pressure is elevated at baseline or cardiac status precludes it (Class I; Level of Evidence B). (Revised recommendation from previous guidelines)

7. Cerebral angioplasty and/or selective intra-arterial vasodilator therapy is reasonable in patients with symptomatic cerebral vasospasm, particularly those who are not rapidly responding to hypertensive therapy (Class IIa; Level of Evidence B). (Revised recommendation from previous guidelines) 
Table 2. Tools available for monitoring and assessment of cerebral vasospasm

\begin{tabular}{|c|c|c|}
\hline Modality & Advantages & Disadvantages \\
\hline $\begin{array}{l}\text { Serial neurological } \\
\text { examination }\end{array}$ & $\begin{array}{l}\text { - Time saving (quick way for assessment) } \\
\text { - Non-invasive } \\
\text { - Minimal cost }\end{array}$ & $\begin{array}{l}\text { - Can be subjective and depends on the } \\
\text { examiner's skill } \\
\text { - Not reliable in poor grade patients }\end{array}$ \\
\hline $\begin{array}{l}\text { Transcranial Doppler } \\
\text { ultrasound (TCD) }\end{array}$ & $\begin{array}{l}\text { - Non-invasive } \\
\text { - Highly specific for proximal MCA vasospasm }\end{array}$ & $\begin{array}{l}\text { - Highly specific for MCA vasospasm only } \\
\text { - Suboptimal sensitivity }\end{array}$ \\
\hline CT angiography (CTA) & $\begin{array}{l}\text { - Non-invasive } \\
\text { - High diagnostic accuracy }\end{array}$ & $\begin{array}{l}\text { - Risk of contrast induced allergic } \\
\text { reactions and renal impairment } \\
\text { - Radiation exposure } \\
\text { - Not available in some low volume institutes } \\
\text { - Overestimation of the vasospasm }\end{array}$ \\
\hline CT perfusion (CTP) & $\begin{array}{l}\text { - Non-invasive } \\
\text { - High diagnostic accuracy }\end{array}$ & $\begin{array}{l}\text { - Radiation and contrast exposure } \\
\text { - Not available in every institute }\end{array}$ \\
\hline $\begin{array}{l}\text { Magnetic resonance } \\
\text { imaging (MRI) }\end{array}$ & $\begin{array}{l}\text { - Non-invasive } \\
\text { - High sensitivity in diagnosing new infarcts }\end{array}$ & $\begin{array}{l}\text { - Not available in every institute } \\
\text { - Expensive for daily monitoring }\end{array}$ \\
\hline MRI Perfusion (PWI) & - Non-invasive & $\begin{array}{l}\text { - Not available in every institute } \\
\text { - Expensive for daily monitoring }\end{array}$ \\
\hline Catheter angiography & - Gold standard diagnostic test & $\begin{array}{l}\text { - Invasive } \\
\text { - Risk of contrast exposure } \\
\text { - Risk of stroke, injury of large vessels, } \\
\text { bleeding, infections, etc. } \\
\text { - Requires availability of neuro- } \\
\text { interventional service }\end{array}$ \\
\hline $\begin{array}{l}\text { Continuous } \\
\text { electroencephalography } \\
\text { cEEG (alpha: delta } \\
\text { ratio) }\end{array}$ & \multicolumn{2}{|c|}{$\begin{array}{l}\text { Investigational } \\
\text { Potential advantages are good spatial resolution, continuous physiological assessment } \\
\text { Disadvantages are need for continuous reading by experience physicians. Not yet } \\
\text { sufficiently validated. }\end{array}$} \\
\hline $\begin{array}{l}\text { Brain tissue oxygen } \\
\text { monitoring }\left(\mathrm{PbtO}_{2}\right)\end{array}$ & \multicolumn{2}{|c|}{$\begin{array}{l}\text { Investigational } \\
\begin{array}{l}\text { Potential advantages are assessment at the tissue of risk. Captures ischemia that may not be } \\
\text { recognized by cerebral perfusion pressure calculation. } \\
\text { Disadvantages are: Poor spatial resolution, invasive. }\end{array}\end{array}$} \\
\hline Cerebral microdialysis & \multicolumn{2}{|c|}{$\begin{array}{l}\text { Investigational } \\
\text { Potential advantages are: Gives additional information at metabolic biochemical level } \\
\text { beyond oxygenation, and blood flow. }\end{array}$} \\
\hline
\end{tabular}

flow velocity; a change in a vessel diameter will be inversely proportional to the blood flow velocity in the same vessel. ${ }^{23}$ It is considered highly specific in detecting vasospasm in the MCA territory and a moderately sensitive diagnostic test when compared to conventional digital subtraction angiography (DSA) which is the gold standard for detection of cerebral arterial narrowing. ${ }^{22}$ A systematic review of 26 reports which compared TCD to conventional angiography showed that TCD is unlikely to demonstrate middle cerebral artery (MCA) spasm if angiography fails to show it, i.e., a low false-positive rate. ${ }^{24}$ Daily TCD is recommended 
and considered reasonable to monitor for vasospasm (Class Ila; Level of Evidence B). ${ }^{4}$ The threshold is less than $120 \mathrm{~cm} / \mathrm{s}$ for absence of vasospasm and more than $200 \mathrm{~cm} / \mathrm{s}$ or a MCA mean cerebral blood flow velocity/extracranial internal carotid artery mean cerebral blood flow velocity more than 6 for the presence of vasospasm. ${ }^{12}$ Other uncommon physiologic modalities for detecting $\mathrm{DCl}$ include brain tissue oxygen monitoring $\left(\mathrm{PbtO}_{2}\right)$, cerebral microdialysis (CMD), and electroencephalogram (EEG); ${ }^{22}$ insufficient data are available at present regarding these modalities.

Radiographic monitoring includes conventional digital subtraction angiography (DSA) which is the gold standard diagnostic method, computed tomography scans which include CT angiography (CTA), and CT perfusion (CTP). Computed tomography angiography has been compared to DSA and has an $87 \%$ accuracy in detecting arterial vasospasm; using CTA as a diagnostic tool has a negative predictive value of $95 \%$ and helps avoid $83 \%$ of unnecessary DSA. ${ }^{25}$ Another study showed a 95.2\% agreement between CTA and DSA in the detection of vasospasm. ${ }^{26}$ Computed tomography perfusion was found to be a superior diagnostic tool for $\mathrm{DCl}$ when compared to CTA; ${ }^{27}$ the criteria for highest diagnostic accuracy with CTP are an increased mean transit time and decreased cerebral blood flow. ${ }^{11,27}$ Computed tomography angiography combined with CTP provides accurate screening to predict $\mathrm{DCl} .{ }^{28}$ Radiographic monitoring is considered a relatively accurate method of arterial vasospasm detection. However, it is not practical on a daily basis unlike TCD, since it carries risk of radiation exposure, and it is unreasonable to expose patients to daily intravenous contrast.

The severity of aneurysmal SAH is usually assessed by the Hunt and Hess scale which also predicts the survival and risks at the time of intervention. ${ }^{29}$ The risk for vasospasm can be assessed by the Fisher $^{6}$ and the modified Fisher scales (Tables 3 and 4). In low risk, good grade patients, it is practical to monitor them with neurological examinations and TCD; new deficits or increased velocities on TCD are an indication for further assessment using CTA, CTP, or DSA. ${ }^{22}$ In high risk, good grade patients who previously underwent CTA, CTP, or DSA, changes
Table 3. Fisher scale for prediction of cerebral vasospasm risk after aneurysmal $\mathrm{SAH}$

- Grade 1: No blood

- Grade 2: Diffuse or thin layer of blood less than $1 \mathrm{~mm}$ thick (interhemispheric, insular, or ambient cisterns)

- Grade 3: Localized clots and/or layers of blood greater than $1 \mathrm{~mm}$ thick in the vertical plane

- Grade 4: Intracerebral or intraventricular clots with diffuse or absent blood in basal cisterns

in neurological status are an indication to start therapy with blood pressure elevation and endovascular intervention. Repeating CTA and CTP should be considered if there is any doubt about the cause of the new deficits or if therapeutic intervention is contraindicated or carries high risk. ${ }^{22}$ In poor grade and sedated patients, clinical examination is very limited, and it is difficult to identify new neurological deficits. In these patients, a change in TCD velocities or the detection of vasospasm on routine CTA or DSA or perfusion deficits on CTP is an indication to initiate therapy for $\mathrm{DCl}$, unless a significant infarction has developed. ${ }^{22}$

\section{B. ORAL NIMODIPINE}

Nimodipine is a calcium antagonist that is indicated in all patients with aneurysmal SAH starting from day 1 following aneurysmal rupture for 21 days, which is the time these patients are at risk for developing vasospasm. Nimodipine administration (Class I, Level of Evidence $\mathrm{A})^{4}$ is the only evidence-based pharmacologic therapy for improving outcomes following

Table 4. Modified Fisher scale for prediction of cerebral vasospasm risk after aneurysmal SAH

- Grade 0: no SAH or IVH

- Grade 1: focal or diffuse, thin SAH, no IVH

- Grade 2: focal or diffuse, thin SAH, with IVH

- Grade 3: focal or diffuse, thick ${ }^{*}$ SAH, no IVH

- Grade 4: focal or diffuse, thick SAH, with IVH

*Hemorrhagic filling in one or more cisterns or fissures.

SAH- subarachnoid hemorrhage; IVH- intraventricular hemorrhage. 
vasospasm. ${ }^{30}$ It does not treat the vasospasm but improves the neurological outcomes by limiting $\mathrm{DCl}$. Calcium antagonists decrease calcium influx to vascular smooth muscle by blocking calcium channels and thus decrease vasospasm. ${ }^{31}$ Randomized trials showed the benefit of oral nimodipine in reducing poor outcomes and secondary ischemia; ${ }^{30,32}$ there is no proof that other routes like intravenous injection improve the outcomes. ${ }^{31}$ The recommended dose of oral nimodipine is $60 \mathrm{mg}$ every 4 hours given for the first 21 days after aneurysmal SAH.

\section{MAgNeSIUM, STATINS, AND ENDOTHELIN ANTAGONISTS}

Magnesium, which acts as a calcium channel blocker and NMDA-receptor antagonist, was hypothesized to decrease poor outcomes in patients with aneurysmal SAH. However, phase-III placebo control trials have failed to show that intravenous infusion of magnesium sulfate is superior to placebo..$^{33,34}$

Statins have neuroprotective effects by antiinflammatory, antioxidant, and antithrombotic effects; ${ }^{35}$ they reduce ischemic stroke risk. Considering these concepts, statins underwent randomized clinical trials aiming to improve outcomes in patients following aneurysmal $\mathrm{SAH}$. As with magnesium, these drugs did not demonstrate any benefit either in short and long term outcomes or in reducing mortality. ${ }^{36}$

Endothelin is a potent vasoconstrictor, and randomized control trials have been conducted to study the effect of endothelin receptor antagonists on the outcomes of SAH patients. The most recent metaanalysis of these trials concluded that there is no benefit in the outcomes. ${ }^{37}$

\section{Hemodynamic augmentation}

The intention of hemodynamic augmentation is to improve cerebral blood flow (CBF) to optimize the cerebral perfusion pressure. Triple-H therapy (hypervolemia, hypertension, and hemodilution) was considered for many decades to increase cerebral blood flow in patients with aneurysmal $\mathrm{SAH}$ and to prevent and treat cerebral vasospasm. However, there is no strong evidence in the medical literature supporting this therapy since most of the studies were non-randomized. ${ }^{22}$ At the current time, Triple-H therapy and its separate components have not been proven to increase CBF in SAH patients and there is no consensus that it should be used. ${ }^{38}$

Hypervolemia has been compared to euvolemia in few prospective randomized studies. ${ }^{39,40}$ These studies failed to demonstrate any difference between hypervolemia and euvolemia to prevent or treat vasospasm. Hypervolemia might be associated with higher risk of complications, such as congestive heart failure and re-bleeding. ${ }^{12,39,41}$ There are some physiological and observational human and animal data to suggest that hypervolemia does not increase cerebral perfusion pressure compared to euvolemia. Multiple modalities are used for volume status monitoring; these include clinical examination, fluid balance, daily weight, BUN: $\mathrm{Cr}$ ratio, central venous pressure, Swan-Ganz catheter, bedside critical care ultrasound, and non-invasive hemodynamic and cardiac monitoring (Table 5).

Induced hypertension (Class I, Level of Evidence B) produces a modest increase in CBF and is recommended in patients with $\mathrm{DCl}$, provided that the aneurysm has been secured. ${ }^{4,22,38}$ The goal is to increase mean arterial pressure (MAP) by $20 \%$ or target a MAP at $100-110 \mathrm{mmHg}$. Some practitioners prefer to target the systolic blood pressure between $180-240 \mathrm{mmHg}$ or MAP $110-140 \mathrm{mmHg}^{42}$ Efforts to reach the target blood pressure in patients with congestive heart failure, myocardial ischemia, and other cardiac comorbidities may be limited to avoid other serious complications that might develop from cardiac decompensation. In patients with signs of vasospasm and an unsecured aneurysm, blood pressure elevation should be cautious. ${ }^{22}$ The preferred vasopressors to induce hypertension are norepinephrine, phenylephrine, and possibly dopamine. ${ }^{22}$

The results of the above recommendations and observations reflect a shift from Triple $\mathrm{H}$ therapy to euvolemic induced-hypertension for treatment of symptomatic cerebral vasospasm. As with all goal directed therapy in critical care, multiple modalities are often used, and care is individualized based on the patient's physiology at any given point in time. 
Table 5. Tools available for monitoring volume status to target euvolemia

\begin{tabular}{|l|l|l|}
\hline Modality & Advantages & Disadvantages \\
\hline $\begin{array}{l}\text { Clinical examination, fluid } \\
\text { balance and daily weight }\end{array}$ & $\begin{array}{l}\text { - Easy and quick tool } \\
\bullet \text { Non-invasive }\end{array}$ & $\begin{array}{l}\text { - Dependent on examiner's skills } \\
\text { Poor sensitivity and specificity }\end{array}$ \\
\hline BUN: Cr ratio & $\bullet$ Non-invasive & $\begin{array}{l}\text { - Not accurate in medical conditions like } \\
\text { kidney disease }\end{array}$ \\
\hline Central venous pressure & $\bullet$ Continuous monitoring & $\begin{array}{l}\text { - Invasive } \\
\text { Requires central venous line with risk of } \\
\text { infections, bleeding, and lung injury } \\
\text { Poor sensitivity and specificity except at } \\
\text { extremes of range }\end{array}$ \\
\hline $\begin{array}{c}\text { Swan-Ganz catheter } \\
\text { monitoring }\end{array}$ & $\begin{array}{l}\text { No advantage } \\
\text { Invasive } \\
\text { Risk of arrhythmias, bleeding, infection, } \\
\text { pneumothorax, and thrombosis }\end{array}$ \\
\hline $\begin{array}{c}\text { Bedside critical care } \\
\text { ultrasound (IVC, EF, } \\
\text { end-diastolic filling) }\end{array}$ & $\begin{array}{l}\text { - Requires additional training of } \\
\text { personnel }\end{array}$ \\
\hline $\begin{array}{l}\text { Non-invasive hemodynamic } \\
\text { and cardiac output } \\
\text { monitoring (Flow Trac }{ }^{\circledR} \text { etc) }\end{array}$ & $\begin{array}{l}\text { - Non-invasive and quick tool for trained } \\
\text { personnel }\end{array}$ & $\begin{array}{l}\text { Impaired sensitivity and specificity in } \\
\text { patients with cardiac arrhythmias }\end{array}$ \\
\hline
\end{tabular}

\section{E. Hemodynamic augmentation}

Intra-arterial infusion of vasodilators and balloon angioplasty are used independently or in combination for treatment of symptomatic vasospasm refractory to medical therapy to prevent worsening neurological deficits. Intra-arterial vasodilators for treatment of vasospasm include papaverine which is the most studied agent. However, with multiple reported side effects, it has been replaced with intra-arterial calcium channel blockers, including verapamil, nimodipine, and nicardipine. ${ }^{43}$ Balloon angioplasty works by mechanical dilation of the intracranial vessels. It leads to durable results but is feasible only with the proximal cerebral vessels, the internal carotid artery, the middle cerebral artery M1 segment, the anterior cerebral artery A1 segment, the basilar artery, and the posterior cerebral artery P1 segment. Prophylactic transluminal balloon angioplasty prior to the onset of vasospasm within 96 hours after aneurysmal SAH in patients with Fisher grade III produced a significant decrease in the number of patients who needed therapeutic angioplasty, but it did not improve in clinical outcomes. Therefore, prophylactic angioplasty is not indicated in patients following aneurysmal $\mathrm{SAH} .{ }^{44}$ balloon angioplasty is reserved for patients with angiographic or clinical vasospasm. Endovascular treatment is repeated as needed, and there is no guideline about the appropriate time to discontinue endovascular management. This depends on the clinical judgement and expertise of the caring team, the response to treatment, the development of new neurological deficits, and the evolution of new infarcts on the follow up scans.

\section{F. Cessation and de-escalating therapy}

The main endpoint triggering de-escalation of therapy is resolution of vasospasm or established infarction in the territory at risk. In good grade patients, with improvement during clinical assessment, cautious de-escalation of therapy should be considered. This can be aided by physiological and TCD monitoring. In poor grade patients, confirmation with a serial TCD, CT perfusion, continuous EEG monitoring, $\mathrm{PbtO}_{2}$ or 
microdialysis is required. If a significant infarction in the territory at risk is confirmed, therapy can be discontinued ${ }^{22}$ Nimodipine is discontinued after 21 days from the day of the hemorrhage.

\section{Conclusions}

Aneurysmal SAH is a serious neurological emergency associated with high morbidity and mortality that requires prompt intervention to secure the ruptured aneurysm. It should be managed in a high-volume center (centers managing $>35 \mathrm{SAH} /$ year). Cerebral vasospasm is the most challenging complication that follows aneurysmal SAH. There is an evidence based consensus that all patients with aneurysmal SAH should be started with oral nimodipine for 21 days and close monitoring with frequent neurological checks and other diagnostic modalities like TCD, CTA, CTP and DSA. Depending on the triggers found during monitoring, patients might qualify for hemodynamic augmentation or endovascular treatment. Magnesium, statins, endothelin antagonists and hypervolemia therapy make no statistical differences in the neurological outcomes. Other monitoring modalities (like EEG, $\mathrm{pbtO}_{2}$, and micro dialysis) are still under investigation.

\begin{abstract}
Article citation: Shehabeldin M, Alderazi YJ. Management of cerebral vasospasm following aneurysmal subarachnoid hemorrhage. The Southwest Respiratory and Critical Care chronicles 2017;5(20):33-43.

From: Department of Neurology, Texas Tech University Health Sciences Center, Lubbock, Texas.

Submitted: $1 / 30 / 2017$

Accepted: $7 / 7 / 2017$

Reviewer: Kenneth Nugent MD

Conflicts of interest: none
\end{abstract}

\section{REFERENCES}

1. Kassell NF, Sasaki T, Colohan AR, Nazar G. Cerebral vasospasm following aneurysmal subarachnoid hemorrhage. Stroke 1985 Jul-Aug;16(4):562-72.
2. Pradilla G, Chaichana KL, Hoang S, Huang J, Tamargo RJ. Inflammation and cerebral vasospasm after subarachnoid hemorrhage. Neurosurg Clin N Am 2010 Apr;21(2):365-79.

3. Rabinstein AA, Friedman JA, Weigand SD, McClelland RL, Fulgham JR, Manno EM, Atkinson JL, Wijdicks EF. Predictors of cerebral infarction in aneurysmal subarachnoid hemorrhage. Stroke 2004 Aug;35(8):1862-6. Epub 2004 Jun 24.

4. Connolly ES Jr et al., American Heart Association Stroke Council; Council on Cardiovascular Radiology and Intervention; Council on Cardiovascular Nursing; Council on Cardiovascular Surgery and Anesthesia; Council on Clinical Cardiology. Guidelines for the management of aneurysmal subarachnoid hemorrhage: a guideline for healthcare professionals from the American Heart Association/American Stroke Association. Stroke 2012 Jun;43(6):1711-37.

5. Lawson MF, Chi YY, Velat GJ, Mocco JD, Hoh BL. Timing of aneurysm surgery: The International Cooperative Study revisited in the era of endovascular coiling. J Neurointerv Surg 2010 Jun;2(2):131-4.

6. Fisher CM, Kistler JP, Davis JM. Relation of cerebral vasospasm to subarachnoid hemorrhage visualized by computerized tomographic scanning. Neurosurgery 1980 Jan;6(1):1-9.

7. Ecker A, Riemenschneider PA. Arteriographic demonstration of spasm of the intracranial arteries, with special reference to saccular arterial aneurysms. J Neurosurg 1951 Nov;8(6):660-7.

8. Weir B, Grace M, Hansen J, Rothberg C. Time course of vasospasm in man. J Neurosurg. 1978 Feb;48(2):173-8.

9. Frontera JA, Fernandez A, Schmidt JM, Claassen J, Wartenberg KE, Badjatia N, Connolly ES, Mayer SA. Defining vasospasm after subarachnoid hemorrhage: what is the most clinically relevant definition? Stroke 2009 Jun;40(6):1963-8.

10. Burch CM, Wozniak MA, Sloan MA, Rothman MI, Rigamonti D, Permutt T, Numaguchi Y. Detection of intracranial internal carotid artery and middle cerebral artery vasospasm following subarachnoid hemorrhage. J Neuroimaging 1996 Jan;6(1):8-15.

11. Sanelli PC, Ugorec I, Johnson CE, Tan J, Segal AZ, Fink M, Heier LA, Tsiouris AJ, Comunale JP, John M, Stieg PE, Zimmerman RD, Mushlin AI. Using quantitative CT perfusion for evaluation of delayed cerebral ischemia following aneurysmal subarachnoid hemorrhage. AJNR Am J Neuroradiol 2011 Dec;32(11):2047-53.

12. Suarez JI. Diagnosis and Management of Subarachnoid Hemorrhage. Continuum (Minneap Minn). 2015 Oct;21(5 Neurocritical Care):1263-87.

13. Labovitz DL, Halim AX, Brent B, Boden-Albala B, Hauser WA, Sacco RL. Subarachnoid hemorrhage incidence among Whites, Blacks and Caribbean Hispanics: The Northern Manhattan Study. Neuroepidemiology 2006;26(3):147-50. 
14. Nieuwkamp DJ, Setz LE, Algra A, Linn FH, de Rooij NK, Rinkel GJ. Changes in case fatality of aneurysmal subarachnoid haemorrhage over time, according to age, sex, and region: a meta-analysis. Lancet Neurol 2009 Jul; 8(7):635-42.

15. Lucke-Wold BP, Logsdon AF, Manoranjan B, Turner RC, McConnell E, Vates GE, Huber JD, Rosen CL, Simard JM. Aneurysmal Subarachnoid Hemorrhage and Neuroinflammation: A Comprehensive Review. Int J Mol Sci. 2016 Apr 2;17(4). pii: E497.

16. Dietrich HH, Dacey RG Jr. Molecular keys to the problems of cerebral vasospasm. Neurosurgery 2000 Mar;46(3):517-30.

17. Hadjikhani N, Sanchez Del Rio M, Wu O, Schwartz D, Bakker D, Fischl B, Kwong KK, Cutrer FM, Rosen BR, Tootell RB, Sorensen AG, Moskowitz MA. Mechanisms of migraine aura revealed by functional MRI in human visual cortex. Proc Natl Acad Sci U S A. 2001 Apr 10;98(8):4687-92. Epub 2001 Apr 3.

18. Dreier JP1, Major S, Manning A, Woitzik J, Drenckhahn C, Steinbrink J, Tolias C, Oliveira-Ferreira AI, Fabricius M, Hartings JA, Vajkoczy P, Lauritzen M, Dirnagl U, Bohner G, Strong AJ; COSBID study group. Cortical spreading ischaemia is a novel process involved in ischaemic damage in patients with aneurysmal subarachnoid haemorrhage. Brain 2009 Jul;132(Pt 7):1866-81.

19. Somjen GG. Mechanisms of spreading depression and hypoxic spreading depression-like depolarization. Physiol Rev 2001 Jul;81(3):1065-96.

20. Kramer DR, Fujii T, Ohiorhenuan I, Liu CY. Cortical spreading depolarization: Pathophysiology, implications, and future directions. J Clin Neurosci 2016 Feb;24:22-7.

21. Leng LZ, Fink ME, Iadecola C. Spreading depolarization: a possible new culprit in the delayed cerebral ischemia of subarachnoid hemorrhage. Arch Neurol 2011 Jan;68(1):31-6.

22. Diringer MN, Bleck TP, Claude Hemphill J 3rd, Menon D, Shutter L, Vespa P, Bruder N, Connolly ES Jr, Citerio G, Gress D, Hänggi D, Hoh BL, Lanzino G, Le Roux P, Rabinstein A, Schmutzhard E, Stocchetti N, Suarez JI, Treggiari M, Tseng MY, Vergouwen MD, Wolf S, Zipfel G; Neurocritical Care Society. Critical care management of patients following aneurysmal subarachnoid hemorrhage: recommendations from the Neurocritical Care Society's Multidisciplinary Consensus Conference. Neurocrit Care 2011 Sep;15(2):211-40.

23. Newell DW, Winn HR. Transcranial Doppler in cerebral vasospasm. Neurosurg Clin N Am. 1990 Apr;1(2):319-28.

24. Lysakowski C, Walder B, Costanza MC, Tramèr MR. Transcranial Doppler versus angiography in patients with vasospasm due to a ruptured cerebral aneurysm: A systematic review. Stroke 2001 Oct;32(10):2292-8.
25. Chaudhary SR, Ko N, Dillon WP, Yu MB, Liu S, Criqui GI, Higashida RT, Smith WS, Wintermark M. Prospective evaluation of multidetector-row CT angiography for the diagnosis of vasospasm following subarachnoid hemorrhage: a comparison with digital subtraction angiography. Cerebrovasc Dis 2008;25(1-2):144-50. Epub 2007 Dec 11.

26. Yoon DY, Choi CS, Kim KH, Cho BM. Multidetector-row CT angiography of cerebral vasospasm after aneurysmal subarachnoid hemorrhage: comparison of volume-rendered images and digital subtraction angiography. AJNR Am J Neuroradiol 2006 Feb;27(2):370-7.

27. Dankbaar JW, de Rooij NK, Velthuis BK, Frijns CJ, Rinkel GJ, van der Schaaf IC. Diagnosing delayed cerebral ischemia with different CT modalities in patients with subarachnoid hemorrhage with clinical deterioration. Stroke 2009 Nov;40(11):3493-8.

28. Wintermark M, Ko NU, Smith WS, Liu S, Higashida RT, Dillon WP. Vasospasm after subarachnoid hemorrhage: utility of perfusion CT and CT angiography on diagnosis and management. AJNR Am J Neuroradiol 2006 Jan;27(1):26-34.

29. Hunt WE, Hess RM. Surgical risk as related to time of intervention in the repair of intracranial aneurysms. J Neurosurg. 1968 Jan;28(1):14-20.

30. Pickard JD, Murray GD, Illingworth R, Shaw MD, Teasdale GM, Foy PM, Humphrey PR, Lang DA, Nelson $\mathrm{R}$, Richards $\mathrm{P}$, et al. Effect of oral nimodipine on cerebral infarction and outcome after subarachnoid haemorrhage: British aneurysm nimodipine trial. BMJ 1989 Mar 11;298(6674):636-42.

31. Dorhout Mees SM, Rinkel GJ, Feigin VL, et al. Calcium antagonists for aneurysmal subarachnoid haemorrhage. Cochrane Database Syst Rev 2007:CD000277.

32. Allen GS, Ahn HS, Preziosi TJ, Battye R, Boone SC, Boone SC, Chou SN, Kelly DL, Weir BK, Crabbe RA, Lavik PJ, Rosenbloom SB, Dorsey FC, Ingram CR, Mellits DE, Bertsch LA, Boisvert DP, Hundley MB, Johnson RK, Strom JA, Transou CR. Cerebral arterial spasm: a controlled trial of nimodipine in patients with subarachnoid hemorrhage. $\mathrm{N}$ Engl J Med 1983 Mar 17;308(11):619-24.

33. Dorhout Mees SM, Algra A, Vandertop WP, van Kooten F, Kuijsten HA, Boiten J, van Oostenbrugge RJ, Al-Shahi Salman R, Lavados PM, Rinkel GJ, van den Bergh WM; MASH-2 Study Group. Magnesium for aneurysmal subarachnoid haemorrhage (MASH-2): a randomized placebo-controlled trial. Lancet. 2012 Jul 7;380(9836):44-9.

34. Wong GK, Poon WS, Chan MT, Boet R, Gin T, Ng SC, Zee $\mathrm{BC}$; IMASH Investigators. Intravenous magnesium sulphate for aneurysmal subarachnoid hemorrhage (IMASH): a randomized, double-blinded, placebo-controlled, multicenter phase III trial. Stroke 2010 May;41(5):921-6. 
35. Vaughan CJ, Delanty N. Neuroprotective properties of statins in cerebral ischemia and stroke. Stroke 1999 Sep; 30(9):1969-73.

36. Kirkpatrick PJ, Turner CL, Smith C, Hutchinson PJ, Murray GD; STASH Collaborators. Simvastatin in aneurysmal subarachnoid haemorrhage (STASH): a multicenter randomized phase 3 trial. Lancet Neurol 2014 Jul;13(7):666-75.

37. Ma J, Huang S, Ma L, Liu Y, Li H, You C. Endothelin-receptor antagonists for aneurysmal subarachnoid hemorrhage: an updated meta-analysis of randomized controlled trials. Crit Care 2012 Oct 18;16(5):R198.

38. Dankbaar JW, Slooter AJ, Rinkel GJ, Schaaf IC. Effect of different components of triple-H therapy on cerebral perfusion in patients with aneurysmal subarachnoid haemorrhage: a systematic review. Crit Care 2010;14(1):R23.

39. Egge A, Waterloo $K$, Sjøholm $H$, Solberg $T$, Ingebrigtsen $T$, Romner B. Prophylactic hyperdynamic postoperative fluid therapy after aneurysmal subarachnoid hemorrhage: a clinical, prospective, randomized, controlled study. Neurosurgery 2001 Sep;49(3):593-605; discussion 605-6.

40. Lennihan L, Mayer SA, Fink ME, Beckford A, Paik MC, Zhang H, Wu YC, Klebanoff LM, Raps EC, Solomon RA. Effect of hypervolemic therapy on cerebral blood flow after subarachnoid hemorrhage: a randomized controlled trial. Stroke 2000 Feb;31(2):383-91.

41. Muench E, Horn P, Bauhuf C, Roth H, Philipps M, Hermann P, Quintel M, Schmiedek P, Vajkoczy P. Effects of hypervolemia and hypertension on regional cerebral blood flow, intracranial pressure, and brain tissue oxygenation after subarachnoid hemorrhage. Crit Care Med 2007 Aug;35(8):184451; quiz 1852.

42. Koenig MA. Management of delayed cerebral ischemia after subarachnoid hemorrhage. Continuum (Minneap Minn). 2012 Jun;18(3):579-97.

43. Pandey AS, Elias AE, Chaudhary N, Thompson BG, Gemmete JJ. Endovascular treatment of cerebral vasospasm: vasodilators and angioplasty. Neuroimaging Clin N Am 2013 Nov;23(4):593-604.

44. Zwienenberg-Lee M, Hartman J, Rudisill N, Madden LK, Smith K, Eskridge J, Newell D, Verweij B, Bullock MR, Baker A, Coplin W, Mericle R, Dai J, Rocke D, Muizelaar JP; Balloon Prophylaxis for Aneurysmal Vasospasm (BPAV) Study Group. Effect of prophylactic transluminal balloon angioplasty on cerebral vasospasm and outcome in patients with Fisher grade III subarachnoid hemorrhage: results of a phase II multicenter, randomized, clinical trial. Stroke 2008 Jun; 39(6):1759-65. 